\title{
FISHING FOR NORTHERN HAWK OWLS NEAR PRINCE ALBERT
}

\section{MYRON BARTON, Box 3083, Prince Albert, Saskatchewan. S6V 7M4}

We have been fortunate to have a Northern Hawk Owl within half a kilometre of our place for the entire winter. The owl was first seen 7 November 1991 and was still there as of 18 February 1992.

It is very tame and has three or four favourite lookout trees very close to the road.

Having read of Robert iNero's success at luring owls to close range using an artificial mouse, I thought I would give it a try. I had trouble finding an artificial mouse around the house, so I finally decided to try a wiener. I got out the fishing rod and attached a wire where the hook would normally be. The wire was inserted into the partially fro- zen wiener and I was ready for action.

Several times I tried casting out the lure and retrieving it in what I considered to be mouse fashion. The owl, however, was not convinced and although he was quite interested, would not cooperate further. It was probably just as well, since I am new to this neighbourhood and the neighbours might think it a bit strange to see someone fishing on the road at $-30^{\circ} \mathrm{C}$.

A few days later, I was able to get a real mouse, which made a meal for the owl when it was released. Wayne Harris banded this owl on 31 December 1991, shown in the photograph below.

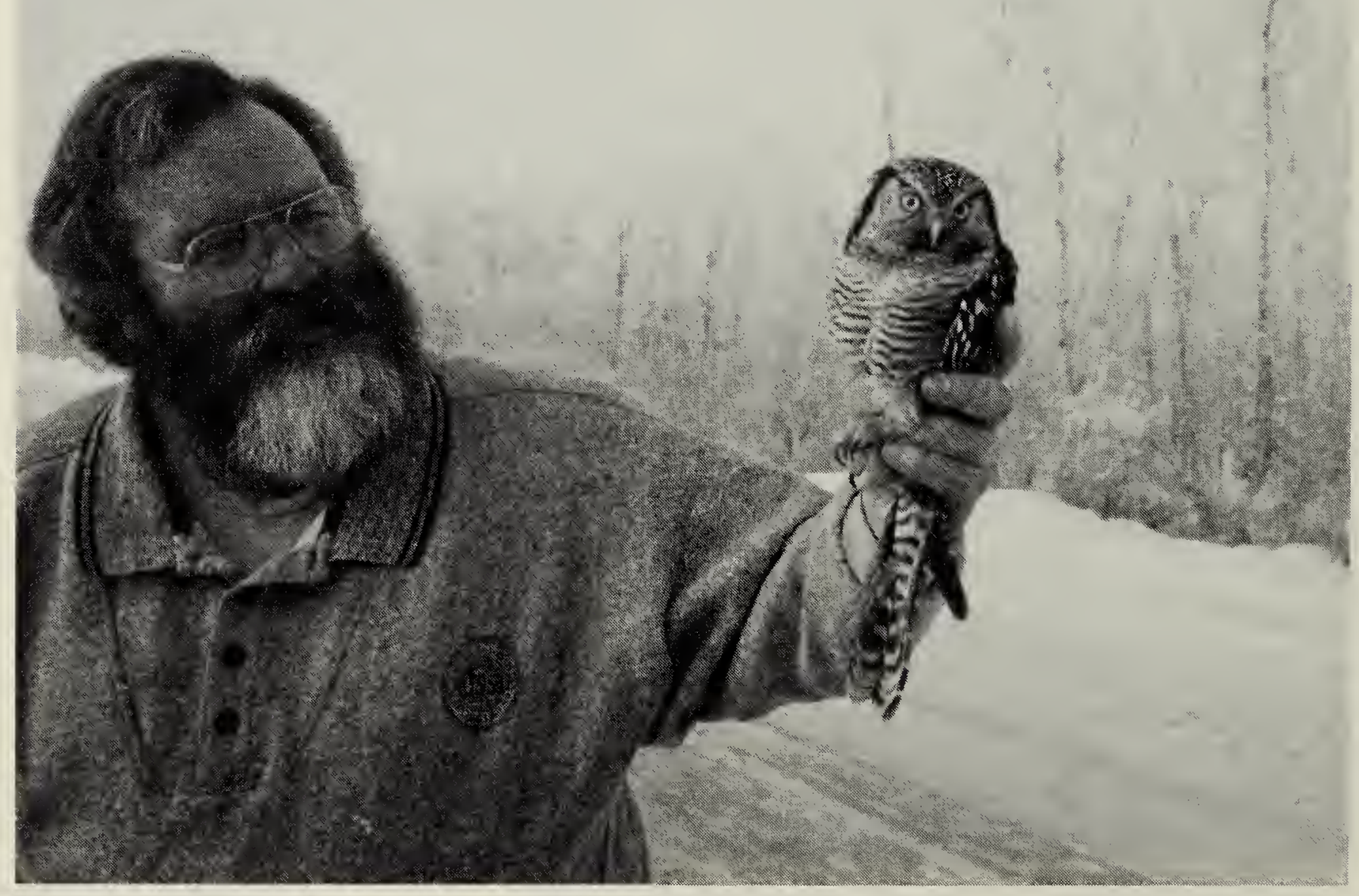

